\title{
Alphabetical paragraphia in a limited middle cerebral artery stroke
}

\author{
Martin Catala, Bertrand Fontaine, Gérald Rancurel
}

\begin{abstract}
A Yugoslavian perfectly bilingual for French and Serb had a limited left middle cerebral artery stroke. He developed a peculiar dysgraphia characterised by the use of Latin characters (French spelling) to transcribe Serb phonemes that would normally have been spelt in the Cyrillic alphabet. This dysgraphia was likely to be due to an impairment of the allographic procedure. It is concluded that allographs of the two alphabets are produced concomitantly in bialphabetical patients during the allographic procedure.
\end{abstract}

(F Neurol Neurosurg Psychiatry 1994;57:649-651)

Writing is a complex procedure that has different sequential stages. During the first part of the process, each word is transformed into a sequence of abstract letters. This transformation may be produced by two different routes in alphabetical languages ${ }^{1}$ : the phonological route and the lexical route. These routes may be impaired by damage to the nervous system, giving rise to a central dysgraphia. The second part of the process allows the transformation of each abstract or conceptual letter form, namely the grapheme, (for example, "F") into fonts (or allographs) that may be executed in various ways (for example, $F, f, f)$. This step is produced letter by letter and the process is still poorly understood. There are at least three successive steps: the sequence of graphemes is temporarily stored in a working memory device called the graphemic buffer; during the allographic procedure, each grapheme is transformed into allographic forms, one of which will be chosen according to the context and the position of the letter in the string; and, finally, the adequate allograph is converted into a motor plan. ${ }^{1-3}$

In fact, the actual processing of written text may be more complex, the different groups of characters (numbers $v$ letters, vowels $v$ consonants) having different status. ${ }^{4}$ Indeed, two patients with selective paragraphia exclusively concerning vowels have already been reported. ${ }^{5}$ The author suggested that vowels and consonants were produced by two different cerebral systems, but he was unable to recognise a unique structure in the $\mathrm{CNS}$ devoted to the processing of vowels, as the first patient had a left parietal infarct and the second a left frontal infarct. In this paper we report a case of a Yugoslavian man with a left frontal infarct associated with a selective dysgraphia. This clinical presentation has been analysed in terms of the mechanisms involved in the allograph selection for a particular grapheme.

\section{Case report}

A 52-year-old right-handed man, born in Yugoslavia and living in France for 25 years, perfectly bilingual in Serb and French, was admitted to hospital for a rapidly reversing right brachiofacial hemiparesis with aphasia. He had smoked two packs of cigarettes daily for 15 years and had stopped smoking five years before admission. He had mild untreated hypertension.

The evening before admission to hospital, he had a sudden right hemiparesis and aphasia. Motor disturbance predominated in the brachiofacial territory and disappeared within 30 minutes. The oral language deficit was characterised by a non-fluent aphasia, both in French and in Serb, and impaired naming. There was no paraphasia or comprehension difficulty. The language deficit cleared within three hours. The next morning, neurological examination disclosed a mild dysarthria and brisk right sided reflexes without Babinski sign. Sensation and visual fields were normal. Two days after admission the patient complained of a peculiar dysgraphia noted while solving Serbian crosswords. Short words (one or two syllables) were correctly written, whereas long words were written with literal paragraphia. For example, he wrote КОНСТУСИОN for КОНСТУСИОН (constitution), НАRОДNИ for НАРОДНИ (nation), ПУТОУАТИ instead of ПҮТОВАТИ (to travel). Analysis of the paragraphia was performed on 30 words and showed that they corresponded to the substitution of a Cyrillic character by its Latin counterpart. Only three pairs of characters were concerned: $((B, V),(P, R),(H, N))$. He was aware of his errors and could correct them after reading his words. Praxis, reading, and oral spelling (both in Serb and in French) were normal. The dysgraphia lasted four days. 


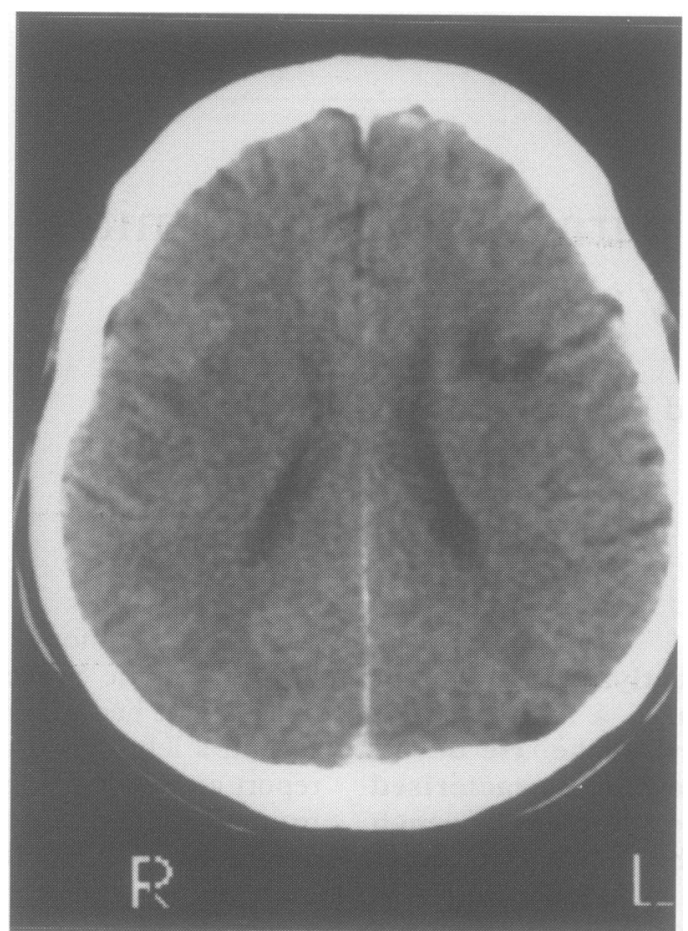

Figure Cerebral CT showing left frontal subcortical hypodensity in the distribution of the superficial middle cerebral artery.

Cerebral CT without contrast injection showed a hypodensity in the left frontal subcortical territory under the middle frontal gyrus $^{6}$ in the distribution of the left superficial middle cerebral artery (figure). Ultrasonic angiology of the cervical arteries did not show any significant vascular lesion. Transthoracic echocardiography revealed a non-obstructive cardiomyopathy with low left ventricular flow. Cardiac catheterisation confirmed a non-obstructive cardiomyopathy with moderate impairment of left ventricular function and showed a left intraventricular thrombus. It was concluded that the stroke was likely due to an embolism from the intraventricular thrombus.

\section{Discussion}

Our patient was Serb and wrote with the Cyrillic alphabet. After arriving in France 25 years previously, he learned French and the Latin alphabet and became bilingual and "bialphabetical". Consequently, phonemes common to Serb and French corresponded to both Cyrillic and Latin characters.

Our patient presented a "pure agraphia" characterised by literal substitutions; he wrote the Latin character instead of the Cyrillic one. For phonemes common to both languages, the correspondence between Cyrillic and Latin alphabets allows the pairs of characters to be classified into three groups. The first group (for example, (Д,D), $(\boldsymbol{U}, \mathbf{I}),(\Phi, F))$ corresponds to pairs of characters in which the Cyrillic one is specific and never used in the latin alphabet. The second group (for example, (A,A), (K,K), (M,M)) corresponds to characters used both in Cyrillic and Latin writing. The third group
$((\mathrm{B}, \mathrm{V}),(\mathrm{H}, \mathrm{N}),(\mathrm{P}, \mathrm{R}),(\mathrm{C}, \mathrm{S}))$ corresponds to pairs of characters in which the Cyrillic one can be used as a Latin character with a different phonological correspondence. Literal substitution, in our patient, belonged to this last group and only implicated consonants. The specificity for consonants is explained by the table of correspondence between the two alphabets and not by an impairment of a putative device specific for consonants. The substitutions concerned pairs of characters (Cyrillic and Latin) that were evoked by the same grapheme, and we consider that they represent different allographs of the same grapheme. Our case suggests that Cyrillic and Latin allographs are generated concomitantly by the same grapheme during the allographic procedure. This type of substitution corresponds to a peripheral agraphia, the problem lying within the allographic procedure. ${ }^{1-3}$ Because of their production, we termed these errors alphabetical paragraphia. Such allographic substitutions have already been noted within a more global writing disorder: A patient reported by $\mathrm{Katz}^{7}$ often intermixed upper and lower letters within a word and a patient reported by Kartsounis ${ }^{8}$ wrote $L$ for 1 and $Q$ for $q$. The localisation of the lesion in these two cases was not stated. Paragraphia appeared for long words (three or more syllables) as occurred for the patients reported by $\mathrm{Katz}^{7}$ and Piccirilli et al. ${ }^{9}$ The increase in error rate with the length of the words was considered by these authors to be an indicator of mnesic impairment involving the graphemic buffer. The literal substitutions by our patient could be explained by a mnesic disturbance affecting the device devoted to the selection of the correct allographic form.

His lesion was located in the subcortical white matter under the middle frontal gyrus. Frontal lesions have been associated with pure agraphia. ${ }^{4}$ Our case was similar to that reported by Albert and Obler. ${ }^{10}$ They described a woman bilingual for Hebrew and English who wrote Hebrew words containing some English letters after bilateral frontal damage caused by a car accident. They did not state, however, if there was any correspondence between the English and Hebrew characters.

This type of literal paragraphia occurred in patients using two different types of alphabet. By contrast, in Japanese patients or in bilingual patients who use two completely different systems for writing, such as syllabic and ideographic characters, this type of paragraphia does not occur. The grapheme production is independent for the two systems and dysgraphia involves predominantly one of the two systems. ${ }^{1112}$ It would be interesting to study such patients who use different writing systems (alphabetical systems of the Occidental languages, alphabetical systems in which vowels and consonants have different status such as the Semitic languages, ideographic systems of the Asiatic languages) to analyse the cerebral connections between these different types of writing. 
We thank Pete Jeffs, PhD, Nicholas K Gonatas, MD, and Nathalie Kubis, MD for critical reading of the manuscript.

1 Bub D, Chertkow H. Agraphia. In: Boller F, Grafman J, eds. Handbook of neuropsychology. Vol 1. Amsterdam: eds. Handbook of neuropsychology. Vol 1. Am
Elsevier Science Publishers, 1988:393-414.

2 Ellis AW. Spelling and writing (and reading and speaking). In: Ellis AW, ed. Normality and pathology in cognitive functions. London: Academic Press, 1982:1 13-46.

3 Shallice T. From neuropsychology to mental structure. Cambridge: Cambridge University Press 1988:130-57.

4 Anderson SW, Damasio AR, Damasio H. Troubled letters but not numbers. Domain specific cognitive impairments following focal damage in frontal cortex. Brain 1990;113:749-66.

5 Cubelli R. A selective deficit for writing vowels in acquired dysgraphia. Nature 1991;353:258-60.
6 Nieuwenhuys R, Voogd J, Van Huijzen C. The human central nervous system. Berlin: Springer-Verlag, 1988.

7 Katz RB. Limited retention of information in the graphemic buffer. Cortex 1991;27:111-9.

Kartsounis LD. Selective lower-case letter ideational dys-

9 Piccirilli M, Petrillo S, Poli R. Dysgraphia and selective impairment of the graphemic buffer. Ital $\mathcal{F}$ Neurol Sci

10 Albert ML, Obler K. The bilingual brain. New York: Academic Press, 1978

11 Lyman RS, Kwan ST, Chao WH. Left occipito-parietal brain tumor with observations in alexia and agraphia. Chin Med f (Engl) 1938;54:491-516.

12 Sasanuma S, Fujimara C. Selective impairment of processing phonetic and non-phonetic transcriptions of words in aphasic patients: Kana and Kanji in visual recognition and writing. Cortex 1971;7:196-218. 